\title{
FUZZY LOGIC APPROACH TO ENERGY PLANNING IN NIGERIA
}

\author{
ADE-IKUESAN OLANIKE OLUFISAYO', ATILOLA MORUFDEEN \\ OLATUNBOSUN ${ }^{1}$, OYEDEJI AJIBOLA OLUWAFEMI ${ }^{2 *}$, \\ ADEYEMI HEZEKIAH OLUWOLE ${ }^{3}$ \\ ${ }^{1}$ Department of Electrical/Electronic Engineering, Olabisi Onabanjo University, P.M.B. \\ 5026, Ifo, Ogun State, Nigeria \\ ${ }^{2}$ Department of Computer Engineering, Olabisi Onabanjo University, P.M.B. 5026, Ifo, \\ Ogun State, Nigeria \\ ${ }^{3}$ Department of Mechanical Engineering, Olabisi Onabanjo University, P.M.B. 5026, Ifo, \\ Ogun State, Nigeria
}

\begin{abstract}
Energy planning is an important tool for power system utility company and consumer's profitability and satisfaction respectively. This paper is a study of energy planning (forecasting) in Ogun state of Nigeria using Fuzzy Logic model. Population and gross domestic product (GDP) are used as the independent variables to forecast load demand based on the previous load demand. After arranging the variables into 5 membership functions and the 19 rules were created, the fuzzy logic model forecast the annual load demand for the next 10 years with a percentage error margin $0.95 \%$ to $21.79 \%$ which results to a mean absolute percentage error (MAPE) of $8.34 \%$. The result of the forecast shows that within the next 10 years, 2019 to 2028, an average power load of $1985.66 \mathrm{MWH}$ will be required.
\end{abstract}

Keywords: energy planning, load forecasting, fuzzy logic, population, GDP, MAPE

\section{INTRODUCTION}

Accurate planning is inevitable in the power system for effective socio-economic growth. Energy planning involves several activities such as load flow, contingency, load security and energy forecasting. However, energy forecast takes a vintage position because other forms of planning depend on it for operation [1-2]. Energy forecasting in the energy industry includes the prediction of the supply, demand and price of electricity, gas, water, and renewable energy. Load forecasting, a form of energy forecasting is predicting the electricity demand of a particular geographical and/or temporal interval into the future [1,3,4]. The primary aim of planning is to ensure future demands are met effectively both economically and in terms of engineering [5].

Load forecasts could either be carried out on a short, medium and long-term basis. In brief, the short term is aligned to a short period, and it contains the forecast for one hour and a week. The medium-term extends from one week to the maximum of a year ahead and in the long-term forecast, the time frame starts from one year to many. Certainly, many methodologies dominate the whole process of load forecasting ranging from regression method, exponential smoothing, stochastic process, ARMA, to data mining etc. As presented in [6], the performance of two (2) Medium-Term Load Forecasting schemes which are the least square approach and regression exponential approach for Ogun State in Nigeria were compared having a MAPE value of $1.82 \%$ and $6.18 \%$ respectively.

\footnotetext{
*Corresponding author, email: oyedeji.ajibola@ oouagoiwoye.edu.ng
}

(C) 2020 Alma Mater Publishing House 
However, the most recent and shared methodology in the present has been subsumed into a term called artificial intelligence (a combination of artificial neural networks (ANN) and fuzzy logic) [1, 7]. The artificial intelligence methods also known as soft-computing techniques, includes Fuzzy Logical System (FLS), Artificial Neural Network (ANN), and Genetic Algorithms' (GA). The fuzzy logic system is utilized for the forecasting in this paper. The origin of the "fuzzy logic" emanates from a theory called fuzzy set created by Dr L.A. Zadeh in the middle of 1960s. The fuzzy logic used a mathematical model which resonates human mental syntax on IF-THEN basis by mirroring a nonlinear relationship between parameters and how they affect the daily electric power load [7-8]. Fuzzification is the process of aligning fuzzy sets with membership functions which carry crisp numerical values. These membership functions have different model classifications; namely, trapezoidal, Gaussian, triangular, etc. The membership function is the attachment of member value to every input space (normally between 0 up to 1 ). The next step is about the fuzzy inference system, and it means that data is taken on a limited basis (IF-THEN) and import to the inference system which analyses the data to produce the forecasted value [89]. Figure 1 shows a typical Fuzzy Logic Model.

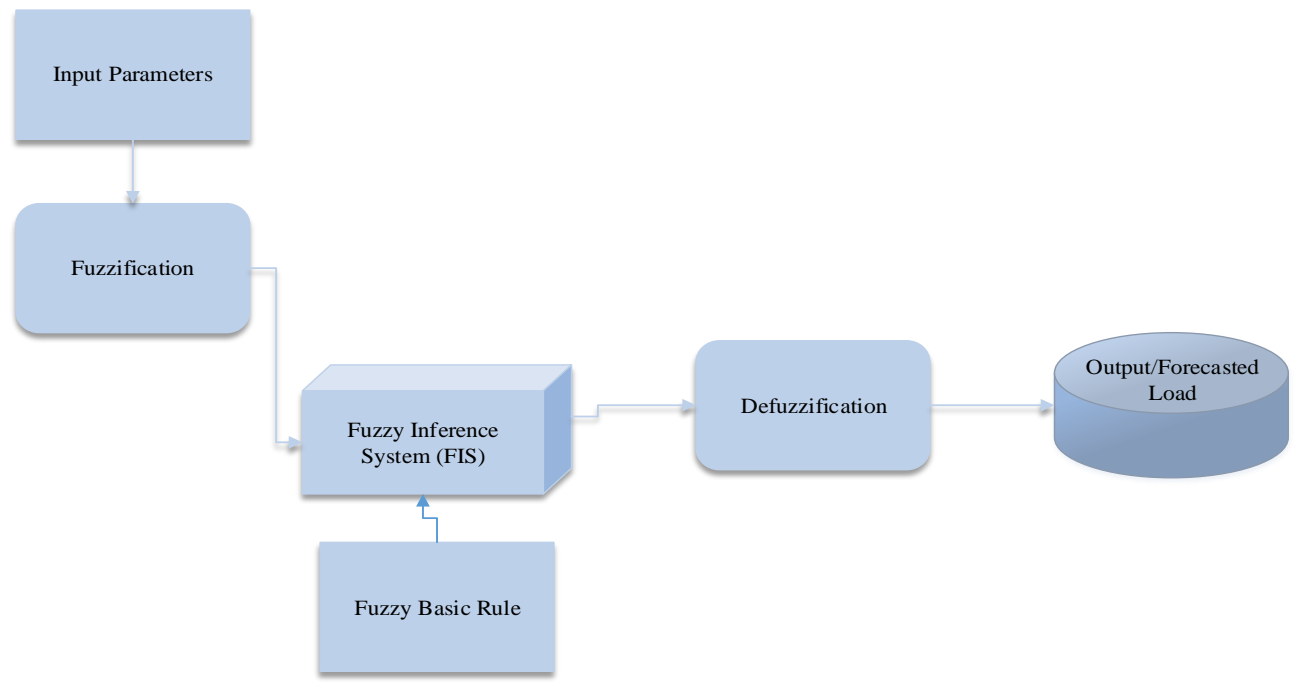

Fig. 1. Block diagram of a fuzzy model.

A study on electric power forecasting in Owerri city (South-East Nigeria) using artificial neural network model, a multilayer time delayed feed-forward artificial neural network trained with error backpropagation algorithm to study the pre-historical load pattern of Owerri city power system network in a supervised training manner was done [5]. After presenting the model with a reasonable number of training samples, which is the historic load demand between 2007 and 2017, the model could forecast correctly the average annual electric power demand in Owerri city for the next ten years (2018 to 2027) as 111.6 MW. This means that the present installed capacity will not be able to adequately serve Owerri city [5].

A fuzzy logic model for long-term load forecasting is developed based on the weather parameters (temperature and humidity) and past energy demand data to forecast a year-ahead load. The fuzzy logic model forecast a yearahead load with a MAPE of $6.9 \%$ and efficiency of $93.1 \%$. The result obtained revealed that the proposed model is capable of predicting future load [10]. A performance evaluation study on a MTLF carried out on a university campus in Nigeria using the regression analysis and ANN models show the latter performing better with a MAPE value of $2.85 \%$ [11].

An energy consumption change forecasting system using the fuzzy logic approach to help manufacturers forecast the energy consumption change due to variations in certain production factors was presented in [12]. To demonstrate how the fuzzy logic approach is applied to a manufacturing system, a case study of the energy consumption forecast in a clothing manufacturing plant has been conducted in an emulated environment. The result of the case indicates a percentage change in the plant's energy consumption after analysing three input parameters which are the daily total mass of clothing produced, the total labour hours of operation and running time of equipment [12].

A fuzzy logic methodology was designed to extract rules from the input variables and provide Brazil's long-term annual electricity demand forecasts with the population and the GDP as input in [13]. The results for the fuzzy 
models had a much better fit than Holt model, according to the estimated MAPE. For total Brazil's model, the fuzzy model produced a percentage mean error of $1.46 \%$, while for the Holt model, this error was $5.81 \%$ depicting a huge difference [13]. Mohamed and Bodger studied a model for electricity forecasting in New Zealand. The model is based on multiple linear regression analysis, taking into account economic and demographic variables [14]. In [15], the authors studied linear regression models for forecasting in Italy, utilizing historical electricity consumption, GDP, GDP per capita and population as variables.

This research aims to implement a fuzzy logic model for long term energy demand forecast for Ogun State, Nigeria. For this research, the following specific objectives should be met:

1. To collect the population, GDP and energy consumption data for Ogun State for 5 years;

2. To build the fuzzy logic model and base rules;

3. To forecast energy demand using fuzzy logic Simulink model for 10 years.

\section{MATERIALS AND METHOD}

The paper studies energy load forecasting method using the fuzzy logic system with population and the gross domestic product (GDP) as the two input/independent variables used to predict the output/dependent variable which is the energy demand. The study was performed for Ogun State, which is a southwestern state in Nigeria. The previous load demand data of Ogun state are gotten from the Ibadan Electricity Distribution Company station in Abeokuta, the population and the Gross Domestic Product (GDP) is gotten from Nigeria Bureau of Statistics (NBS). The data was for 5 years from 2014 to 2018. These data are collected to be trained and tested for the prediction of future load demand.

\subsection{Population}

According to the 2006 census, the population of Ogun state was 3,751,140, it was projected to 4,742,477 in 2013 using the population projection formula in equation (1). The projected population in 2013 was used as the base population for the projection of the quarterly population of Ogun state. The population projection formula is given by Malthusian population growth equation [1].

$$
\mathbf{N}_{t}=\mathbf{P} \times \mathbf{e}^{\mathbf{r} \times \mathbf{t}}
$$

where $\mathbf{N}_{\boldsymbol{t}}$ is the number of people at the future time, $\mathbf{P}$ is the population at the beginning time, 2013 projected population is used as the base population, in this case, $\mathbf{e}$ is the base of natural logarithm which equals to 2.71828, $\mathbf{r}$ population growth rate, Ogun state has $\mathbf{3 . 3 5} \%$ growth rate, $\mathbf{t}$ is the period involved.

Table 1. Quarterly population, GDP and actual energy demand of Ogun State from 2014-2018.

\begin{tabular}{|c|c|c|c|c|}
\hline Year & Period & Population & GDP $(=\mathrm{N}=$ million $)$ & Actual Load (KWH) \\
\hline \multirow{4}{*}{2014} & Q1 & 4782362 & $450,942.91$ & $156,593.96$ \\
\hline & Q2 & 4822583 & $469,810.03$ & $194,643.66$ \\
\hline & Q3 & 4863141 & $510,541.64$ & $198,605.19$ \\
\hline & Q4 & 4904041 & $530,147.32$ & $217,681.31$ \\
\hline \multirow{4}{*}{2015} & Q1 & 4945285 & $481,289.81$ & $172,833.67$ \\
\hline & Q2 & 4986876 & $493,666.15$ & $203,064.38$ \\
\hline & Q3 & 5028816 & $539,031.42$ & $220,856.24$ \\
\hline & Q4 & 5071109 & $555,749.02$ & $247,834.92$ \\
\hline \multirow{4}{*}{2016} & Q1 & 5113758 & $497,655.02$ & $179,696.38$ \\
\hline & Q2 & 5156766 & $506,233.29$ & $206,733.28$ \\
\hline & Q3 & 5200135 & $547,962.25$ & $230,271.48$ \\
\hline & Q4 & 5243869 & $568,503.54$ & $260,563.99$ \\
\hline \multirow{4}{*}{2017} & Q1 & 5287971 & $648,211.69$ & $183,024.34$ \\
\hline & Q2 & 5332443 & $670,235.40$ & $208,585.94$ \\
\hline & Q3 & 5377290 & $728,725.94$ & $234,451.57$ \\
\hline & Q4 & 5422514 & $763,103.59$ & $266,109.80$ \\
\hline \multirow{4}{*}{2018} & Q1 & 5468118 & $737,516.74$ & $254,141.07$ \\
\hline & Q2 & 5514106 & $759,685.97$ & $233,030.10$ \\
\hline & Q3 & 5560481 & $828,451.21$ & $230,760.78$ \\
\hline & Q4 & 5607245 & $872,440.88$ & $226,984.34$ \\
\hline
\end{tabular}


Table 1 shows the quarterly population from 2014 to 2018, which gives 20 rows of data as calculated from equation (1). From the table, it can be seen that the population was projected to be $4,782,362$ by the first quarter of 2014 and by the fourth quarter of 2018 , the population was projected to be $5,607,245$.

\subsection{Gross domestic point (GDP)}

The Gross Domestic Point is one of the major factors used in forecasting long term energy need, as it is the monetary market value of all goods and services produced in a specific period, often annually. These measures depend on the industrial and commercial sector of a country which requires high electricity to meet their specification. This implies that the higher the GDP, the higher the energy demanded since they would be many sectors doing activities or the available sectors increases their rate of production, which thereby increase the GDP of the country.

Ogun state GDP was gotten from National Bureau of Statistics (NBS) websites, the Nigeria quarterly GDP was gotten from the Central Bank of Nigeria $(\mathrm{CBN})$ website to get the quarterly GDP of Ogun state. This was calculated by checking the percentage of Ogun state annual GDP in Nigeria's annual GDP. The rate gotten from the relationship was then used to estimate Ogun state quarterly GDP by multiplying it with Nigeria quarterly GDP. Table 1 above shows Ogun state's quarterly GDP from 2014 - 2018.

\subsection{Energy demand}

Ogun state monthly load demand for 5 years from 2014 - 2018 was obtained from Ibadan Electricity Distribution Company (IBEDC), Abeokuta business division. There are six Business Hubs (BH) in the state, the previous data demanded from each of the BHs was acquired and added. The total load data gotten from the addition was divided into quarterly data since other variables are in the quarter. Table 1 shows the quarterly energy demand data of Ogun state for 2014 - 2018.

\subsection{Fuzzy logic for forecasting}

The structure of the fuzzy logic system comprises the input and output variables. For this research, the input variables are population, GDP, and the output is the forecasted load. Figure 2 presents the structure of the fuzzy logic system including inputs and the output.

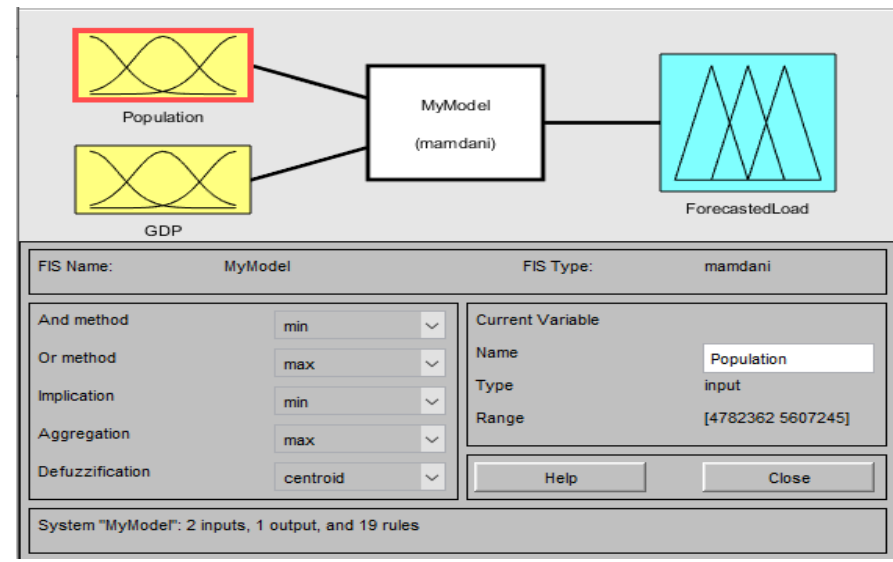

Fig. 2. Fuzzy system structure.

Forecasting with fuzzy logic is implemented in MATLAB, Fuzzy logic designer library by inputting the command fuzzy on the MATLAB command window. The following are the steps carried out on the fuzzy logic designer:

1. Enter the input and output variables;

2. Fuzzify the loaded variables into their membership function;

3. Generate the fuzzy rule base;

4. Defuzzify by showing the rule viewer;

5. Design the Simulink's model;

6. Forecast.

\subsubsection{Fuzzification and membership function assignment}

Fuzzification is the act of dividing the data into a membership function. Some membership functions used in fuzzy logic includes the triangular, trapezoidal and bell shapes. For this research, a triangular membership function which 
comprises of 5 membership functions (Very Low $=$ VL, Low $=\mathrm{L}$, Medium = M, High = H, Very High = VH) is used for both input and output data. Figures 3, 4 and 5 show the membership function of the population, GDP and forecasted load datasets respectively.

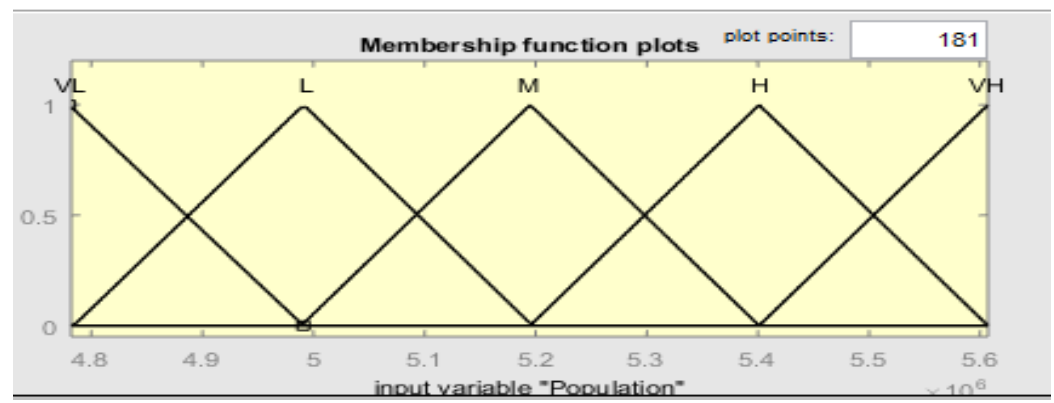

Fig. 3. Population triangular membership function.

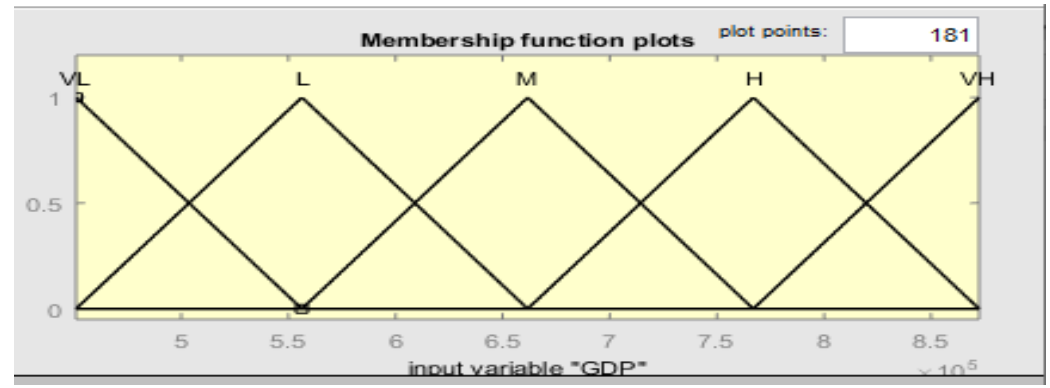

Fig. 4. GDP triangular membership function.

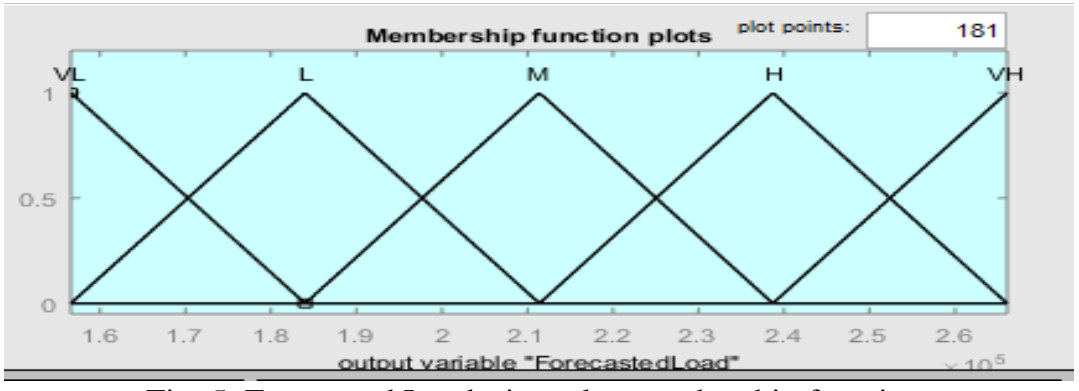

Fig. 5. Forecasted Load triangular membership function.

\subsubsection{Fuzzy rule base}

This part is the heart of the fuzzy system. The heuristic knowledge of the forecast is stored in terms of "IF-THEN" rules. It sends information to the fuzzy inference system, which evaluates the gained information to get the load forecasted output. In this study 19 fuzzy rules are formulated with some of the fuzzy rules shown as follows.
IF (Population is VL) AND (GDP is VL) THEN (ForecastedLoad is VL)
IF (Population is L) AND (GDP is VL) THEN (ForecastedLoad is L)
IF (Population is M) AND (GDP is M) THEN (ForecastedLoad is M)
IF (Population is H) AND (GDP is H) THEN (ForecastedLoad is $\mathrm{H}$ )
IF (Population is VH) AND (GDP is VH) THEN (ForecastedLoad is VH)
IF (Population is VL) OR (GDP is VL) THEN (ForecastedLoad is L)
IF (Population is L) AND (GDP is VL) THEN (ForecastedLoad is M)
IF (Population is M) AND (GDP is VL) THEN (ForecastedLoad is L)

\subsubsection{Deffuzication}

Deffuzication is the final stage in the fuzzy system showing the fuzzy logic system in a rule-based view. It shows that the system is ready for forecasting once you input the variables. Figure 6 shows how the fuzzy system in MATLAB toolbox works for the sample inputs. 


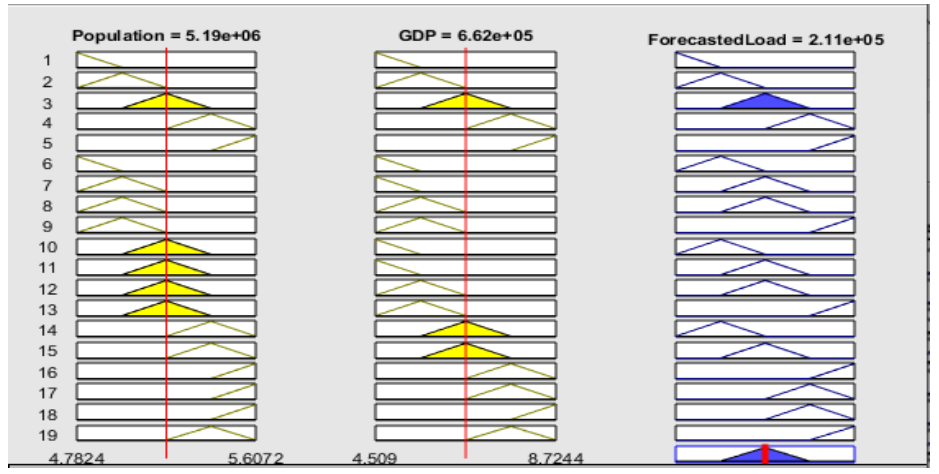

Fig. 6. Defuzzify output for one sample data.

\section{RESULTS AND DISCUSSION}

Forecasted results from the Fuzzy logic model on the load data from IBEDC, Ogun state, are presented and discussed in this section. The result of the fuzzy logic model analysis shows that the forecasted energy consumption for Ogun State is 243,672.69 MWh by the fourth quarter in the year 2018 as against the actual energy consumption of 226,984.34 MWh recorded during the same period.

Known historical data sets of 2014-2018 were used to determine the accuracy level of the forecasted load data of the same period and duration. In each case, the absolute percentage error is computed in Table 2 using equation (2). The accuracy of the results is evaluated using a common evaluation statistic called the mean absolute percentage error (MAPE) calculated with the formula in equation (3) [10, 17].

$$
\text { Absolute Percentage Error (APE) }=\left|\frac{\text { Actual Load-Forecasted load }}{\text { Actual load }}\right| \times 100
$$

Mean Absolute Percentage Error (MAPE) $=\frac{1}{N} \sum_{i=1}^{N}\left|\frac{\text { Actual Load-Forecasted Load }}{\text { Actual Load }}\right| \times 100$

Table 2 shows the quarterly actual load, fuzzy forecasted load, the absolute percentage error and the mean absolute percentage error from 2014 to 2018.

Table 2. Actual and forecasted load.

\begin{tabular}{|c|c|c|c|c|}
\hline Year & Period & Actual Load (KWH) & Forecasted Load (KWH) & APE (\%) \\
\hline \multirow{4}{*}{2014} & Q1 & $156,593.96$ & $179,072.53$ & 14.35 \\
\hline & Q2 & $194,643.66$ & $192,438.12$ & 1.13 \\
\hline & Q3 & $198,605.19$ & $206,754.11$ & 4.10 \\
\hline & Q4 & $217,681.31$ & $210,253.92$ & 3.41 \\
\hline \multirow{4}{*}{2015} & Q1 & $172,833.67$ & $210,502.69$ & 21.79 \\
\hline & Q2 & $203,064.38$ & $211,427.68$ & 4.12 \\
\hline & Q3 & $220,856.24$ & $211,270.31$ & 4.34 \\
\hline & Q4 & $247,834.92$ & $211,259.22$ & 14.76 \\
\hline \multirow{4}{*}{2016} & Q1 & $179,696.38$ & $209,634.97$ & 16.66 \\
\hline & Q2 & $206,733.28$ & $212,146.71$ & 2.62 \\
\hline & Q3 & $230,271.48$ & $224,288.49$ & 2.60 \\
\hline & Q4 & $260,563.99$ & $222,761.19$ & 14.51 \\
\hline \multirow{4}{*}{2017} & Q1 & $183,024.34$ & $203,630.79$ & 11.26 \\
\hline & Q2 & $208,585.94$ & $200,568.75$ & 3.84 \\
\hline & Q3 & $234,451.57$ & $221,034.96$ & 5.72 \\
\hline & Q4 & $266,109.80$ & $240,284.15$ & 9.70 \\
\hline \multirow{4}{*}{2018} & Q1 & $254,141.07$ & $224,476.16$ & 11.67 \\
\hline & Q2 & $233,030.10$ & $235,249.75$ & 0.95 \\
\hline & Q3 & $230,760.78$ & $242,721.55$ & 5.18 \\
\hline & Q4 & $226,984.34$ & $243,672.69$ & 7.35 \\
\hline
\end{tabular}


The results obtained from the fuzzy logic are compared with the actual load demand from 2014-2018 and shows that the absolute percentage error ranges from $0.95 \%$ to $21.79 \%$ as presented in Table 2 above. MAPE computed using equation (3) is $8.34 \%$ which shows that there is a good level of accuracy between the forecasted load and the actual load for the period. This value depicts that the level of deviation from the actual value is low and high accuracy.

The Pearson correlation coefficient is used to measure the strength of a linear association between two variables as presented in equation (4).

$$
\text { Pearson correlation coefficient }=\frac{n\left(\sum x y\right)-\sum x \sum y}{\sqrt{\left.\left.\left[n\left(\sum x^{2}\right)-\left(\sum x\right)^{2}\right)\right]\left[n\left(\sum y^{2}\right)-\left(\sum y\right)^{2}\right)\right]}}
$$

where: $x$ is the actual load and $y$ is the forecasted load.

Table 3. Pearson Correlation coefficient table.

\begin{tabular}{|c|c|c|c|c|c|c|}
\hline Year & Period & $\mathbf{X}$ & $\mathbf{Y}$ & XY & $\mathrm{X}^{2}$ & $\mathbf{Y}^{2}$ \\
\hline \multirow{4}{*}{2014} & Q1 & 156594 & 179072.5 & $2.8042 \mathrm{E}+10$ & 24521668308 & 32066971001 \\
\hline & $\mathbf{Q 2}$ & 194643.7 & 192438.1 & $3.7457 \mathrm{E}+10$ & 37886154378 & 37032430029 \\
\hline & Q3 & 198605.2 & 206754.1 & $4.1062 \mathrm{E}+10$ & 39444021495 & 42747262002 \\
\hline & Q4 & 217681.3 & 210253.9 & $4.5768 \mathrm{E}+10$ & 47385152723 & 44206710875 \\
\hline \multirow{4}{*}{2015} & Q1 & 172833.7 & 210502.7 & $3.6382 \mathrm{E}+10$ & 29871477486 & 44311382497 \\
\hline & Q2 & 203064.4 & 211427.7 & $4.2933 \mathrm{E}+10$ & 41235142425 & 44701663870 \\
\hline & Q3 & 220856.2 & 211270.3 & $4.666 \mathrm{E}+10$ & 48777478747 & 44635143887 \\
\hline & Q4 & 247834.9 & 211259.2 & $5.2357 \mathrm{E}+10$ & 61422147571 & 44630458035 \\
\hline \multirow{4}{*}{2016} & Q1 & 179696.4 & 209635 & $3.7671 \mathrm{E}+10$ & 32290788985 & 43946820647 \\
\hline & Q2 & 206733.3 & 212146.7 & $4.3858 \mathrm{E}+10$ & 42738649060 & 45006226564 \\
\hline & Q3 & 230271.5 & 224288.5 & $5.1647 \mathrm{E}+10$ & 53024954501 & 50305326746 \\
\hline & Q4 & 260564 & 222761.2 & $5.8044 \mathrm{E}+10$ & 67893592885 & 49622547770 \\
\hline \multirow{4}{*}{2017} & Q1 & 183024.3 & 203630.8 & $3.7269 \mathrm{E}+10$ & 33497909032 & 41465498636 \\
\hline & Q2 & 208585.9 & 200568.8 & $4.1836 \mathrm{E}+10$ & 43508094366 & 40227823477 \\
\hline & Q3 & 234451.6 & 221035 & $5.1822 \mathrm{E}+10$ & 54967538675 & 48856453542 \\
\hline & Q4 & 266109.8 & 240284.2 & $6.3942 \mathrm{E}+10$ & 70814425656 & 57736472741 \\
\hline \multirow{4}{*}{2018} & Q1 & 254141.1 & 224476.2 & $5.7049 \mathrm{E}+10$ & 64587683461 & 50389546408 \\
\hline & Q2 & 233030.1 & 235249.8 & $5.482 \mathrm{E}+10$ & 54303027506 & 55342444875 \\
\hline & Q3 & 230760.8 & 242721.6 & $5.6011 \mathrm{E}+10$ & 53250537586 & 58913750834 \\
\hline & Q4 & 226984.3 & 243672.7 & $5.531 \mathrm{E}+10$ & 51521890605 & 59376379852 \\
\hline SUM & & 4326466 & 4313449 & $9.40 \mathrm{E}+11$ & $9.53 \mathrm{E}+11$ & $9.36 \mathrm{E}+11$ \\
\hline
\end{tabular}

From Table 3, $\sum X=4326466.4, \sum Y=4313448.74, \sum X Y=9.40 \times 10^{11}, \sum X^{2}=9.53 \times 10^{11}, \sum Y^{2}=9.36 \times$ $10^{11}$.

Then, correlation coefficient $=\frac{20 \times\left(9.4025 \times 10^{11}\right)-4326466.4 \times 4313448.74}{\sqrt{\left[20\left(9.53 \times 10^{11}\right)-\left(4326466.4^{2}\right)\right]\left[20\left(9.36 \times 10^{11}\right)-\left(4313448.74^{2}\right)\right]}}=\mathbf{0 . 7 2 5}$

Pearson correlation coefficient is 0.725 which shows that there is a strong correlation between the actual and forecasted load. The degree of accuracy as calculated with MAPE using the formula in equation 3 was $8.34 \%$ between the forecasted load and the actual load.

Table 4 shows the projected quarterly population and GDP for 10 years, from 2019 to 2028 while Table 5 presents the annual projected population. GDP and load consumption for the same period.

Table 5 shows the projected annual population, GDP and the fuzzy forecasted load for 2019-2028, the GDP in million naira and forecasted load demand in megawatts-hour (MWH). The fuzzy logic model was used to forecast the total energy demand for the next 10 years, this shows that by the end the year 2019, 2022, 2025, and 2028, an average load of 1325.42 MWH, 1494.02 MWH, 2437.27MWH, and 2807.42 MWH will be demanded 
respectively. This shows that with an increase in the population in the state, the energy load demand also increases. The forecasted load for the year 2028 represents over $100 \%$ increment over the 2019 forecasted load.

Table 4. Projected population and GDP for the year 2019-2028.

\begin{tabular}{|c|c|c|c|}
\hline Year & Duration & Population & GDP $(=\mathrm{N}=$ million $)$ \\
\hline \multirow{4}{*}{2019} & Q1 & 5654403 & 903761.5 \\
\hline & $\mathbf{Q 2}$ & 5701957 & 936206.6 \\
\hline & $\mathbf{Q 3}$ & 5749912 & 969816.4 \\
\hline & Q4 & 5798269 & 1004633 \\
\hline \multirow{4}{*}{2020} & Q1 & 5847034 & 1040699 \\
\hline & Q2 & 5896208 & 1078060 \\
\hline & Q3 & 5945796 & 1116763 \\
\hline & Q4 & 5995801 & 1156854 \\
\hline \multirow{4}{*}{2021} & Q1 & 6046227 & 1198385 \\
\hline & Q2 & 6097077 & 1241407 \\
\hline & Q3 & 6148354 & 1285974 \\
\hline & Q4 & 6200063 & 1332140 \\
\hline \multirow{4}{*}{2022} & Q1 & 6252206 & 1379964 \\
\hline & Q2 & 6304789 & 1429505 \\
\hline & Q3 & 6357813 & 1480824 \\
\hline & Q4 & 6411283 & 1533986 \\
\hline \multirow{4}{*}{2023} & Q1 & 6465203 & 1589056 \\
\hline & Q2 & 6519576 & 1646103 \\
\hline & Q3 & 6574407 & 1705198 \\
\hline & Q4 & 6629699 & 1766415 \\
\hline \multirow{4}{*}{2024} & Q1 & 6685456 & 1829829 \\
\hline & Q2 & 6741682 & 1895520 \\
\hline & Q3 & 6798380 & 1963569 \\
\hline & Q4 & 6855556 & 2034061 \\
\hline \multirow{4}{*}{2025} & Q1 & 6913212 & 2107084 \\
\hline & Q2 & 6971353 & 2182728 \\
\hline & Q3 & 7029984 & 2261088 \\
\hline & Q4 & 7089107 & 2342261 \\
\hline \multirow{4}{*}{2026} & Q1 & 7148727 & 2426348 \\
\hline & Q2 & 7208849 & 2513454 \\
\hline & Q3 & 7269477 & 2603687 \\
\hline & Q4 & 7330614 & 2697160 \\
\hline \multirow{4}{*}{2027} & Q1 & 7392266 & 2793988 \\
\hline & Q2 & 7454436 & 2894292 \\
\hline & Q3 & 7517129 & 2998197 \\
\hline & Q4 & 7580350 & 3105832 \\
\hline \multirow{4}{*}{2028} & Q1 & 7644101 & 3217332 \\
\hline & Q2 & 7708390 & 3332834 \\
\hline & Q3 & 7773218 & 3452483 \\
\hline & Q4 & 7838592 & 3576427 \\
\hline
\end{tabular}

Table 5. Forecasted load demand for the next 10 years.

\begin{tabular}{|l|c|c|c|}
\hline Year & Projected Population & Projected GDP (million Naira) & Forecasted load (MWH) \\
\hline $\mathbf{2 0 1 9}$ & 5798269 & 3814417.18 & 1325.42 \\
\hline $\mathbf{2 0 2 0}$ & 5995801 & 4392376.13 & 1434.52 \\
\hline $\mathbf{2 0 2 1}$ & 6200063 & 5057907.17 & 1450.66 \\
\hline $\mathbf{2 0 2 2}$ & 6411283 & 5824279.22 & 1494.02 \\
\hline $\mathbf{2 0 2 3}$ & 6629699 & 6706771.64 & 1652.39 \\
\hline $\mathbf{2 0 2 4}$ & 6855556 & 7722978.95 & 2251.60 \\
\hline $\mathbf{2 0 2 5}$ & 7089107 & 8893161.59 & 2437.27 \\
\hline $\mathbf{2 0 2 6}$ & 7330614 & 10240649.83 & 2464.64 \\
\hline $\mathbf{2 0 2 7}$ & 7580350 & 11792308.93 & 2538.61 \\
\hline $\mathbf{2 0 2 8}$ & 7838592 & 13579074.80 & 2807.42 \\
\hline
\end{tabular}




\section{CONCLUSION}

The main objectives were as follows:

1. To estimate the energy consumption and GDP for Ogun State.

2. To forecast the future growth of these energy demands and GDP using a fuzzy logic model.

In this research, the fuzzy logic methodology for long term load forecasting is presented, and some evidence for the high electricity consumption growth rate has been explained by present and past events. The need for longrange demand forecasts was fully justified. The forecasting is carried out by using population and gross domestic point as the inputs and the forecasted load as the output. Nineteen IF-THEN rules-based were generated based on the relationship between population, GDP and previous load data after each of the variables have been divided into five membership function during the fuzzification process. Load forecasting was done with an error margin of 0.95 to $21.79 \%$ and the mean absolute percentage error (MAPE) of $8 \%$.

As electricity markets have deregulated in Nigeria over the last decade, accurate load forecasts have become a vital part of a utility's long, medium, and short-term generation and procurement planning. An inaccurate load forecast can have severe consequences for customers in the form of higher rates and unsatisfactory services. With the year 2028 energy load demand forecasted to be over $2807 \mathrm{MWH}$, the stakeholders in the power sector must start planning to build more resources as the present installed capacity would not be able to meet the needs of the customers to forestall any power outage which would negatively affect the GDP of the state.

\section{REFERENCES}

[1] Ade-Ikuesan, O.O., Osifeko, M.O., Okakwu, I.K., Folaranmi, K.S., Alao, P.O., Prediction of electricity consumption demand pattern for 2018 in Ogun State, Nigeria, Journal of Applied Sciences and Environmental Management, vol. 22, no. 6, 2018, p. 883-887.

[2] Amlabu, C.A., Agber, J.U., Onah, C.O., Mohammed, S.Y., Electric load forecasting: a case study of the nigerian power sector, International Journal of Electrical Power and Energy Systems, vol. 2, no. 10, 2013, p. 2327.

[3] Idoniboyeobu, D.C., Ogunsakin, A.J., Wokoma, B.A., Forecasting of electrical energy demand in Nigeria using modified form of exponential model, American Journal of Engineering Research, vol. 7, 2018, p. 122-135.

[4] Ghanbari, A., Hadavandi, E., Abbasian-Naghneh, S., Comparison of artificial intelligence-based techniques for short term load forecasting, Proceedings - 3rd International Conference on Business Intelligence and Financial Engineering, BIFE 2010, p. 6-10.

[5] James, A.E., Ogar, V.N., Moses, I.I., Artificial neural network for energy demand forecast, International Journal of Electrical and Electronic Science, vol. 5, no. 1, 2018, p. 8-13.

[6] Olabode, O.E., Okakwu, I.K., Ade-Ikuesan, O.O., Fajuke, I.D., Performance evaluation of medium-term load forecasting approaches: a case study of Ogun State, Nigeria, Journal of Advances in Science and Engineering, vol. 1, no. 2, 2018, p. 9-16.

[7] Ammar, N., Sulaiman, M., Nor, A.F.M., Analysis load forecasting of power system using fuzzy logic and artificial neural network, Journal of Telecommunication, Electronic and Computer Engineering, vol. 9, no. 3, 2017, p. 181-192.

[8] Kumar, S.A., Khatoon, S., Muazzam, M., Chaturvedi, D.K., Network and complex systems an overview of electricity demand forecasting techniques, Network and Complex Systems, vol. 3, no. 2, 2013, p. 38-48.

[9] Ali, A.T., Tayeb, E.B.M., Shamseldin, Z.M., Short term electrical load forecasting using fuzzy logic, International Journal of Advancement in Engineering Technology, Management and Applied Science, vol. 3, no. 11, 2016, p. 131-138.

[10] Ali, D., Yohanna, M., Puwu, M.I., Garkida, B.M., Long-term load forecast modelling using a fuzzy logic approach, Pacific Science Review A: Natural Science and Engineering, 2015, p. 1- 5.

[11] Samuel, I.A., Emmanuel, A., Odigwe, I.A., Felly-Njoku, F.C.A., Comparative study of regression analysis and artificial neural network methods for medium-term load forecasting, Indian Journal of Science and Technology, vol. 10, no. 10, 2017, p. 1-7.

[12] Lau, H.C.W., Cheng, E.N.M., Lee, C.K.M, Ho, G.T.S., A fuzzy logic approach to forecast energy consumption change in a manufacturing system, Expert Systems with Applications, vol. 34, 2018, p. 1813-1824. [13] Torrini, F.C., Souza, R.C., Oliveira, F.L.C., Pessanha, J.F.M., Long term electricity forecast in Brazil: A fuzzy logic approach, Socio-Economic Planning Sciences, vol. 54, 2016, p. 18-27.

[14] Mohamed, Z., Bodger, P., Forecasting electricity consumption in New Zealand using economic and 
demographic variables, Energy, vol. 30, no. 10, 2005, p. 1833-1843.

[15] Bianco, V., Manca, O., Nardini, S., Electricity consumption forecasting in Italy using linear regression models, Energy, vol. 34, 2009, p. 1413-1421.

[16] Khair, U., Fahmi, H., Hakim, S., Al, Rahim, R., Forecasting error calculation with mean absolute deviation and mean absolute percentage error, Journal of Physics: Conference Series, vol. 930, no. 1., 2017.

[17] Kim, S., Kim, H., A new metric of absolute percentage error for intermittent demand forecasts, International Journal of Forecasting, vol. 32, no. 3, 2016, p. 669-679. 